\title{
Temporal Trends in the Unmet Health Care Needs of Canadian Stroke Survivors
}

\author{
Manav V. Vyas(10, Jiming Fang, Moira K. Kapral(1)
}

\begin{abstract}
Background: Stroke survivors have higher unmet health care needs than the general population. However, it is unclear whether such needs have changed over time, and whether these have been affected by the introduction of integrated systems of stroke care. Methods: We used data from the Canadian Community Health Surveys between 2000 and 2014. We developed multivariable log-binomial generalized estimating equations to obtain adjusted risk ratios (aRRs) of unmet health care needs in stroke survivors compared to the general population, and over time. We conducted a difference in differences analysis to determine the association between the implementation of integrated systems of stroke care and unmet health care needs. Results: Data from 350,084 respondents were included in the study; $8072(2.3 \%)$ were stroke survivors. Compared to the general population, stroke survivors were more likely to report unmet health care needs (aRR 1.27; 95\% CI, 1.22-1.32). The unmet health care needs reported by stroke survivors were lower after compared to before 2006 (15.8\% vs. 31.9\%, $P<0.001)$. After accounting for temporal trends, there was no association between the implementation of integrated systems of stroke care and change in unmet health care needs of stroke survivors. However, this requires cautious interpretation due to limitations in the data available for this study. Conclusions: Unmet health care needs of stroke survivors have reduced over time but remain higher than the general population. Future research should focus on identifying stroke- and policyrelated factors to mitigate disparities in health care access for stroke survivors.
\end{abstract}

RÉSUMÉ : Les besoins non comblés en matière de soins de santé des survivants canadiens à un AVC : des tendances temporelles. Contexte : Les besoins non comblés en matière de soins de santé des survivants à un AVC sont plus nombreux que ceux de la population en général. Cela dit, on comprend encore mal dans quelle mesure ces besoins ont changé au fil du temps ou à l'inverse s'ils ont été affectés par la mise sur pied de systèmes intégrés de soins en ce qui regarde les AVC. Méthodes : Nous avons fait appel aux données de l'Enquête sur la santé dans les collectivités canadiennes qui concernent les années 2000 à 2014. Pour comparer ces besoins non comblés particuliers à ceux de la population en général, nous avons développé des équations d'estimation généralisées à partir de régressions logistiques binomiales multivariables (multivariable log binomial generalized estimating equations). Cela nous a permis d'obtenir le rapport de risque ajusté (RRA) au sujet de ces mêmes besoins. Grâce à la méthode des doubles différences, nous avons également effectué une analyse afin de déterminer l'association existant entre la mise sur pied de systèmes intégrés de soins en ce qui regarde les AVC et la présence de besoins de santé non comblés. Résultats : Des données concernant 350084 répondants ont été inclues dans cette étude. Au total, 8072 individus étaient des survivants à un AVC, soit 2,3\%. Si on les compare à la population générale, ces survivants étaient plus susceptibles de faire état de besoins non comblés (RRA 1,27 ; IC $95 \%, 1,22$ - 1,32). Ces derniers se sont par ailleurs révélés moins nombreux après l'année 2006 $(15,8 \%$ contre $31,9 \%, p<0,001)$. Après avoir tenu compte de tendances temporelles, aucune association entre la mise sur pied de systèmes intégrés de soins et des changements quant aux besoins non comblés des survivants à un AVC n'a été observée. Dans le cadre de cette étude, de tels résultats exigent toutefois une interprétation prudente en raison de données limitées. Conclusions : Les besoins non comblés des survivants à un AVC ont eu tendance à diminuer au fil du temps mais ils demeurent plus nombreux que ceux de la population en général. Du coup, les recherches futures devraient mettre l'accent sur les facteurs reliés aux AVC et aux politiques publiques afin d'atténuer les disparités en matière d'accès aux soins de santé pour les survivants à un AVC.

Keywords: Unmet health care needs, Stroke, Difference in differences, Integrated stroke systems

doi:10.1017/cjn.2019.319

Can J Neurol Sci. 2020; 47: 176-182

\section{INTRODUCTION}

Self-reported unmet health care need is often used as a marker of access to health care and has been included as an indicator by various national and international organizations and institutions monitoring health. ${ }^{1}$ It is defined as the difference between health services that are considered necessary for a particular health problem compared to services that are received. ${ }^{2}$ Stroke is one of the major causes of disability worldwide. ${ }^{3}$ Previous research suggests that adult stroke survivors have higher rates of unmet social and health care needs compared to the general population. ${ }^{4-6}$ Furthermore, perceived poor access to care has been associated with higher rates of hospitalization for chronic diseases. ${ }^{7}$ Thus,

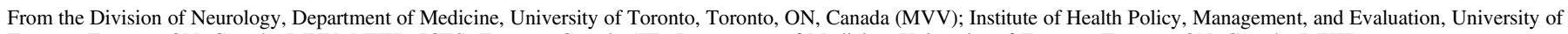
Toronto, Toronto, ON, Canada (MVV, MKK); ICES, Toronto, Canada (JF); Department of Medicine, University of Toronto, Toronto, ON, Canada (MKK)

Received March 20, 2019. Final Revisions Submitted October 17, 2019. Date of Acceptance October 18, 2019.

Correspondence to: Manav V. Vyas, Division of Neurology, Department of Medicine, University of Toronto, Toronto, ON, Canada. Email: manav.vyas@mail.utoronto.ca 
evaluating the burden of unmet health care needs in stroke survivors is important for health care planning and delivery.

Integrated systems of stroke care that aim to coordinate optimal care across an entire region are recommended by professional stroke societies and may be associated with a reduction in the risk of death and disability after stroke. ${ }^{8-10} \mathrm{In}$ 2000, the province of Ontario was among the first North American jurisdictions to launch an integrated system of stroke care delivery, with full implementation in 2005. Similar organized stroke systems were implemented in five other provinces by 2006. Although there were variations in the way that the stroke systems were implemented in different provinces, common elements included the development of regional strategies for providing stroke care, the designation of certain hospitals as "comprehensive stroke centers" capable of providing thrombolysis and other advanced interventions, and the promotion of evidence-based stroke care. We aimed to study temporal trends in the self-reported unmet health care needs of adult stroke survivors and to determine the impact of integrated systems of stroke care on these needs.

\section{Methods}

\section{Data Sources}

We used public-use microdata files of the Canadian Community Health Survey (CCHS) cycles 2000-2001, 2003, 2005, 2010, 2012, and 2014 available under a data liberation initiative at the University of Toronto and pooled them to form the study cohort. CCHS is a nationwide cross-sectional survey of households that uses three sampling frameworks: area frame, telephone frame, and random digit dialing. ${ }^{11}$ People living on Indian Reserves and Crown Lands, institutional residents, and full-time members of the Canadian forces are not included in the survey. Information on various factors is collected over telephone by a trained interviewer using well-developed survey questionnaire. We included information from those over the age of 40 years and excluded information from respondents in the Northwest Territories, Yukon and Nunavut due to lack of information on stroke services in these jurisdictions.

\section{Exposure, Outcome, and Intervention}

Information on stroke was obtained by asking, "Do you suffer from effects of a stroke?." The respondent could answer "yes," "no," or not respond. This was dichotomized and observations with missing values were excluded in the final analysis.

The primary outcome was self-perceived unmet health care need, which was ascertained by asking, "During the past 12 months, was there ever a time when you felt that you needed health care but you didn't receive it?" and the respondent could answer, "yes," "no," or not respond. This was dichotomized and observations with missing values were not included in the final analysis. In the 2012 survey, questions on unmet health care needs were only included in selected provinces: Ontario, British Columbia, and Nova Scotia. In a sensitivity analysis, the data from this cycle were excluded.

A binary variable, intervention, was created based on the province of residence of the respondent. Those in the six provinces that implemented integrated systems of stroke care (Ontario, British Columbia, Alberta, Nova Scotia, Prince Edward Island, and Quebec) were deemed to have received the intervention, while the four that did not have such systems (Newfoundland, New Brunswick, Manitoba, and Saskatchewan) formed the comparison group without the intervention. In addition, a binary variable, time, corresponding to before and after the implementation of stroke systems, was created by classifying data from CCHS cycles 2000-2001, 2003, and 2005 as before and from CCHS cycles 2007-2008, 2010, 2012, and 2014 as after.

\section{Statistical Analyses}

We compared the characteristics of stroke survivors before the intervention in provinces with the intervention compared to those without. The same was repeated for the time after intervention. We used $t$-tests or Wilcox rank sum tests to assess differences in continuous variables, and $\chi^{2}$ tests to assess differences in categorical variables.

We developed a multivariable log-binomial generalized estimating equations model, accounting for clustering among provinces, with stroke as the independent variable of interest and unmet health care needs as the dependent variable. The log-binomial model has been shown to be conservative compared to logistic models, especially for cross-sectional data. ${ }^{12} \mathrm{We}$ adjusted for demographic information including age (10-year age groups, with 60-69 years as the reference category), sex (male as reference category), immigration status (non-immigrant as reference category), ethnic minority (Caucasian as reference category), marital status (married or common law as reference category, with single and widow or separated as other categories), education (3-level categorical scale: less than grade 12 as the reference category, greater than grade 12 , postgraduate certificate or postgraduate degree), risk factors including smoking status (3-level categorical scale: current, former, and never; current as reference category), alcohol use (current vs. not currently drinking, the latter is reference), hypertension, diabetes, and heart disease (self-reported health conditions, binary variables). We chose these variables based on prior knowledge of factors that are related to both stroke and unmet health care needs, and to reflect what has been previously accounted when studying unmet health care needs. ${ }^{6}$ We did not include sampling weights of the CCHS cycle. Key assumptions of model fit, multicollinearity, and impact of influential observations were assessed. Using subgroup analyses, we plotted the trend of adjusted risk ratio (aRR) of having unmet health care needs among stroke survivors compared to the general population in provinces with and without intervention for each CCHS cycle. Then, we obtained aRRs of unmet care needs of stroke survivors compared to the general population before and after 2006, in provinces with and without the intervention using subgroup analyses. Lastly, we obtained the difference in differences (DiD) estimate by adding a three-way interaction term of time and intervention and stroke. The assumption of parallel trends associated with the DiD approach was assessed by the trend plots described above.

We created a subsample by only including stroke survivors. Using this sample, we identified the predictors of unmet care needs in stroke survivors. We also performed the DiD analyses in this cohort using a two-way interaction between time and intervention.

To address the possibility that a change in unmet care needs of stroke survivors could be attributable to underlying temporal trends rather than the intervention, we performed the same 
analyses in patients with migraine and cancer, separately. The results of all analyses were reported with 95\% CI around the estimates and $P$-values. A two-tailed alpha level of 0.05 was set as a cutoff for statistical significance. All data analyses were performed using SAS 9.4 Copyright $^{\circledR}$ 2002-2012 by SAS Institute Inc., Cary, NC, USA.

\section{Results}

We included data from a total of 350,084 participants, with the majority $(n=283,373,80.9 \%)$ living in provinces where an integrated stroke system was implemented. Provinces that did not receive the intervention had lower immigrant density and a lower proportion of respondents with postgraduate education than those that received the intervention, both before and after 2006 (Table 1). Before 2006, the proportion of stroke survivors who reported unmet health care needs was lower in provinces with the intervention compared to those without $(30.7 \%$ vs. $36.5 \%$, $P<0.001)$. This difference was eliminated after $2006(16.2 \%$ vs. $13.5 \%, P=0.19$ ).

The aRR of having unmet health care needs in stroke survivors compared to the general population was 1.27 (95\% CI, 1.221.32) (Supplementary Table 1), with similar findings in provinces with and without integrated systems of stroke care (Figures 1 and 2). We ensured that model assumptions for multicollinearity, model fit, and overspecification were appropriately met. Among stroke survivors, younger age (40-49 years), low income, diabetes, and heart disease predicted a higher risk of having unmet health care needs (Table 2).

After accounting for temporal trends, there was no association between the implementation of integrated systems of stroke care and unmet health care needs of stroke survivors relative to the general population ( $P$-value for three-way interaction term $=0.63)$ (Supplementary Table 2$)$. These results did not differ significantly when data from the 2012 cycle were excluded in sensitivity analyses. When restricted to stroke survivors only, the improvement in unmet health care needs after 2006 was greater in provinces without integrated systems of care than in provinces with such systems $(P$-value for two-way interaction term $=0.024)$ (Supplementary Table 2$)$.

Patients with migraine and cancer had a higher risk of unmet health care needs compared to the general population, with an aRR 1.21 (95\% CI, 1.19-1.24) for migraine and an aRR 1.49 (95\% CI, 1.45-1.53) for cancer. In provinces with integrated systems of stroke care, unmet health care needs of cancer survivors improved after 2006, but worsened for migraine sufferers (Figure 1).

\section{Discussion}

We found that Canadian stroke survivors had higher selfperceived unmet health care needs than the general population. Younger age, the presence of comorbid conditions, and low selfrated health predicted higher unmet health care needs among stroke survivors. While the proportion of stroke survivors with unmet health care needs decreased between 2000 and 2014, after accounting for temporal trends there was no association between implementation of integrated systems of stroke care in 2006 and unmet health care needs of stroke survivors.

Our findings of higher unmet health care needs in patients with a chronic medical condition (stroke, migraine, and cancer) compared to the general population are consistent with previous research with one study reporting a cumulative impact of chronic conditions on the odds of unmet health care needs. ${ }^{6,13}$ Although a prior study did not find an association between stroke and unmet health care needs, it only included information from the 2001 to 2005 CCHS cycles and did not account for provincial clustering. ${ }^{6}$ In contrast, a study from Australia reported that up to $84 \%$ of stroke survivors had unmet health care needs. ${ }^{14}$ Lack of rehabilitation services and insufficient social supports were considered the most common causes of unmet health care needs by stroke survivors. ${ }^{14,15}$

Consistent with previous research in Canada, we found a higher risk of unmet health care needs in stroke survivors who also had comorbid chronic conditions such as heart disease or diabetes. ${ }^{6}$ A UK-based study found that younger stroke survivors were more likely than older ones to report unmet needs for intellectual fulfilment and family support. ${ }^{16}$ Among Australian stroke survivors, age greater than 65 years was associated with a lower adjusted incidence rate ratio (aIRR) of unmet health care needs (aIRR $0.62 ; 95 \% \mathrm{CI}$ $0.50-0.77) .{ }^{17}$ Consistent with this, we found that younger age was associated with higher unmet health care needs among stroke survivors, confirming the social and mental health needs of young stroke survivors. ${ }^{5}$ While other studies administered survey questionnaires to stroke survivors in a particular jurisdiction, we used a population-based sample from national surveys which may explain the differences in the magnitude of association between age and unmet health care needs in stroke survivors. ${ }^{16,17}$

The improvement in unmet health care needs of stroke survivors over the study period is encouraging and aligns with overall improvements in the quality of stroke care in Canada and other high-income countries over the past decades. ${ }^{18}$ Despite using DiD analysis, a robust method of treatment effect estimation for policy interventions, we found no association between the implementation of integrated systems of stroke care and improvements in unmet health care needs after stroke. In addition, in the sample restricted to stroke survivors only, the improvement in unmet health care needs of stroke survivors after 2006 was greater in provinces without integrated systems of stroke care compared to the provinces with these systems. This may be explained by underlying temporal trends in unmet health care needs in the general population which, if not accounted for, can produce biased estimates in the DiD analysis. ${ }^{19}$

Strengths of our study include the use of a nationally representative sample, the ability to account for clustering among provinces, and the use of advanced statistical analytical methods for assessment of a policy intervention. However, some limitations merit discussion. First, the validation of self-reported stroke in CCHS is low (kappa $0.36,95 \%$ CI $0.34-0.39$ ) compared to a case definition of stroke of one hospital admission with a cardiovascular disease diagnosis code; however, misclassification of stroke is unlikely to be related to province of residence, the implementation of integrated system of stroke care, or to time. ${ }^{20}$ Second, we did not have information on the time between the survey date and that of stroke events. We also did not have any information on stroke type or severity, associated deficits, processes of stroke care, or discharge destination, all of which could potentially influence our primary outcome. We did not have information on nonrespondents which may limit the generalizability of our findings. Third, the unmet health care needs reported by stroke survivors may be due to factors others than stroke, and thus may not be affected by the 
Table 1: Characteristics of adult Canadian stroke survivors using data from the Canadian Community Health Surveys (2001-2014)

\begin{tabular}{|c|c|c|c|c|}
\hline \multirow{4}{*}{ Characteristics } & \multicolumn{4}{|c|}{ Before or after the implementation of integrated stroke systems $\$$} \\
\hline & \multicolumn{2}{|c|}{ Before } & \multicolumn{2}{|c|}{ After } \\
\hline & \multicolumn{4}{|c|}{ Integrated stroke systems (present or absent) ${ }^{\epsilon}$} \\
\hline & Present $n=4052$ & Absent $n=1111$ & Present $n=2330$ & Absent $n=\mathbf{5 7 9}$ \\
\hline \multicolumn{5}{|l|}{ Total number $(n), \%$} \\
\hline Female & $2121(52.3)$ & $582(52.4)$ & $1168(50.1)$ & $302(52.2)$ \\
\hline Ethnic minority & $223(5.7)$ & $56(5.2)$ & $206(9.3)$ & $49(8.7)$ \\
\hline Immigrant & $767(19.4)$ & $68(6.3)$ & $430(19.3)$ & $43(7.6)$ \\
\hline \multicolumn{5}{|l|}{ Age in years } \\
\hline $40-49$ & $240(5.8)$ & $44(4.0)$ & $109(4.7)$ & $10(1.7)$ \\
\hline $50-59$ & $538(13.3)$ & $123(11.0)$ & $299(12.8)$ & $72(12.4)$ \\
\hline $60-69$ & $942(23.3)$ & $234(21.1)$ & $598(25.7)$ & $147(25.4)$ \\
\hline $70-79$ & $1353(33.4)$ & $340(30.6)$ & $724(31.0)$ & $176(30.4)$ \\
\hline Above 80 & $979(24.2)$ & $370(33.3)$ & $600(25.8)$ & $174(30.1)$ \\
\hline \multicolumn{5}{|l|}{ Marital status } \\
\hline Married or common-in-law & $2024(50.0)$ & $542(48.8)$ & $1135(48.9)$ & $300(52.0)$ \\
\hline Widow or separated & $290(7.2)$ & $65(5.9)$ & $213(9.2)$ & $47(8.1)$ \\
\hline Single & $1733(42.8)$ & $503(45.3)$ & $975(42.0)$ & $230(39.9)$ \\
\hline \multicolumn{5}{|l|}{ Lifestyle factors } \\
\hline $\begin{array}{l}\text { Ever smoker versus never } \\
\text { smoker }\end{array}$ & $743(18.4)$ & $183(16.5)$ & $388(16.8)$ & $87(15.1)$ \\
\hline $\begin{array}{l}\text { Current alcohol drinker versus } \\
\text { not current drinker }\end{array}$ & $2332(58.7)$ & $533(48.7)$ & $1331(58.9)$ & $295(51.7)$ \\
\hline \multicolumn{5}{|l|}{ Comorbid conditions } \\
\hline Hypertension & $2356(58.4)$ & $665(60.2)$ & $1418(61.2)$ & $374(64.6)$ \\
\hline Diabetes mellitus & $915(22.6)$ & $283(25.6)$ & $606(26.1)$ & $168(29.0)$ \\
\hline Heart disease & 1558 (38.6) & $427(38.7)$ & $882(38.3)$ & $231(40.5)$ \\
\hline \multicolumn{5}{|l|}{ Self-perceived health } \\
\hline Poor & 993 (24.6) & $266(24.1)$ & $540(23.2)$ & $130(22.7)$ \\
\hline Fair & $1471(36.4)$ & $377(34.2)$ & $737(31.8)$ & $194(34.0)$ \\
\hline Good & $1053(26.0)$ & $314(28.4)$ & $671(28.9)$ & $171(30.0)$ \\
\hline Very good & $417(10.3)$ & $125(11.3)$ & $305(13.2)$ & 65 (11.4) \\
\hline Excellent & $109(2.7)$ & $22(2.0)$ & $66(2.9)$ & $11(1.9)$ \\
\hline \multicolumn{5}{|l|}{ Education } \\
\hline$<12$ grade & $1847(47.1)$ & $668(62.1)$ & 746 (33.6) & $217(38.9)$ \\
\hline At least 12 grade & $540(13.8)$ & $115(10.7)$ & $344(15.5)$ & $88(15.8)$ \\
\hline Postsecondary training & $1534(39.1)$ & $292(27.2)$ & $1129(50.9)$ & $253(45.3)$ \\
\hline \multicolumn{5}{|l|}{ Personal income (in $\$ C A D)^{£}$} \\
\hline No income & $94(2.8)$ & $14(1.6)$ & $19(1.0)$ & $6(1.3)$ \\
\hline$<20,000$ & $1436(43.1)$ & $460(50.9)$ & $845(44.0)$ & $224(47.3)$ \\
\hline $20-39,999$ & $1095(32.8)$ & $308(34.1)$ & $653(34.0)$ & $156(32.9)$ \\
\hline $40-59,999$ & $496(14.9)$ & $85(9.4)$ & $252(13.1)$ & $57(12.0)$ \\
\hline $60-79,999$ & $171(5.1)$ & $24(2.7)$ & $81(4.2)$ & $16(3.3)$ \\
\hline$>80,000$ & $43(1.3)$ & $13(1.3)$ & $71(3.7)$ & $15(3.2)$ \\
\hline Unmet health care needs & $1242(30.7)$ & $404(36.5)$ & $336(16.2)$ & $51(13.5)$ \\
\hline
\end{tabular}

${ }^{£}$ Before 2006, personal income categories were no income, <15,000, 15-29,000, 30-49,000, 50-79,000, and over 80,000.

${ }^{\$}$ Before here refers to before integrated stroke systems were implemented (2006), after refers to after their introduction (2006 onwards).

${ }^{€}$ Present and absent refer to presence or absence of integrated stroke systems. 


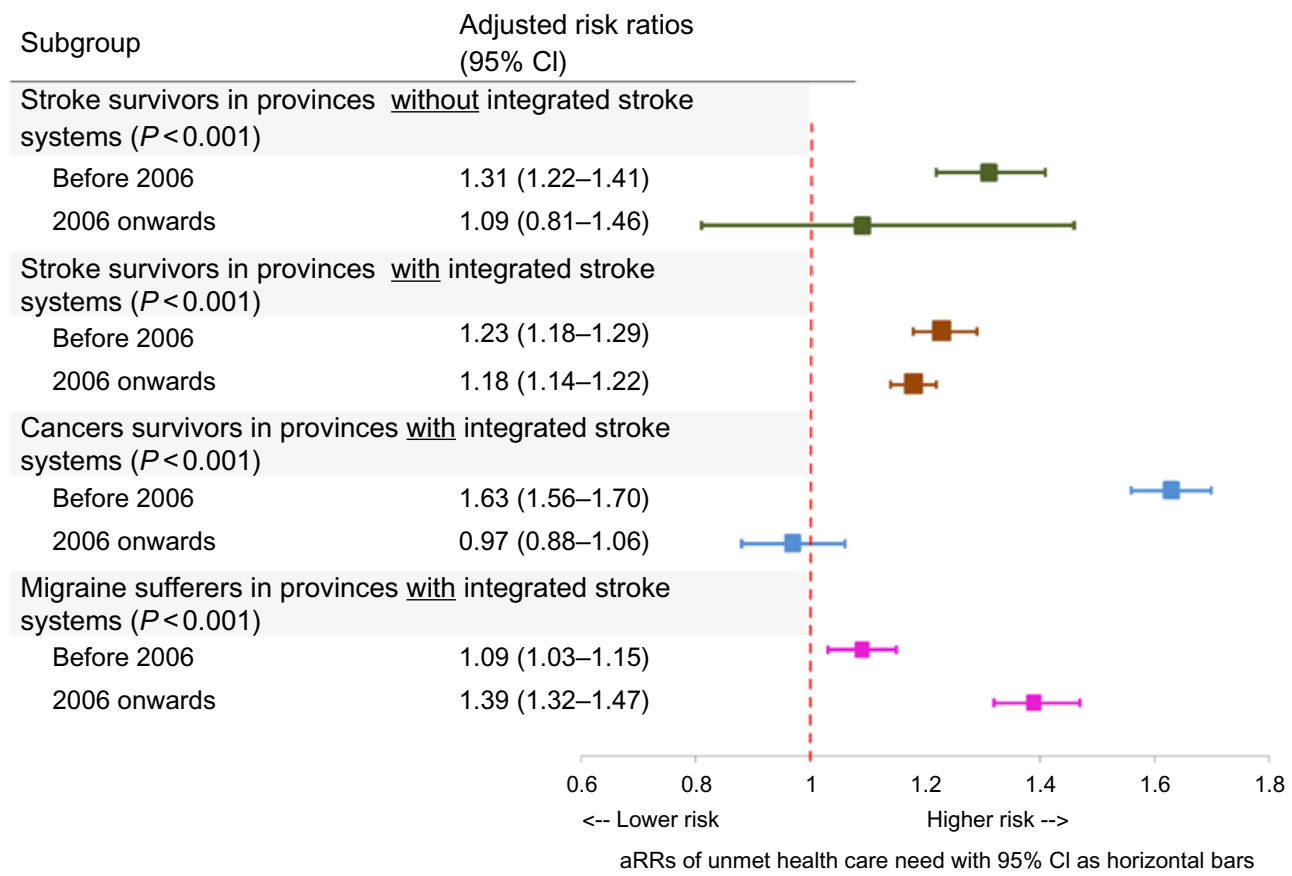

Figure 1: Unmet health care needs in Canadians with disease (stroke, cancer, or migraine) compared to the general population, measured as aRRs, before and after introduction of integrated systems of stroke care (year 2006) using data from Canadian Community Health Surveys (2000-2014 cycles). Note: Confidence intervals for cancer subgroup are not adjusted for clustering. $P$-values in the parenthesis represent the significance of interaction term (disease*time).

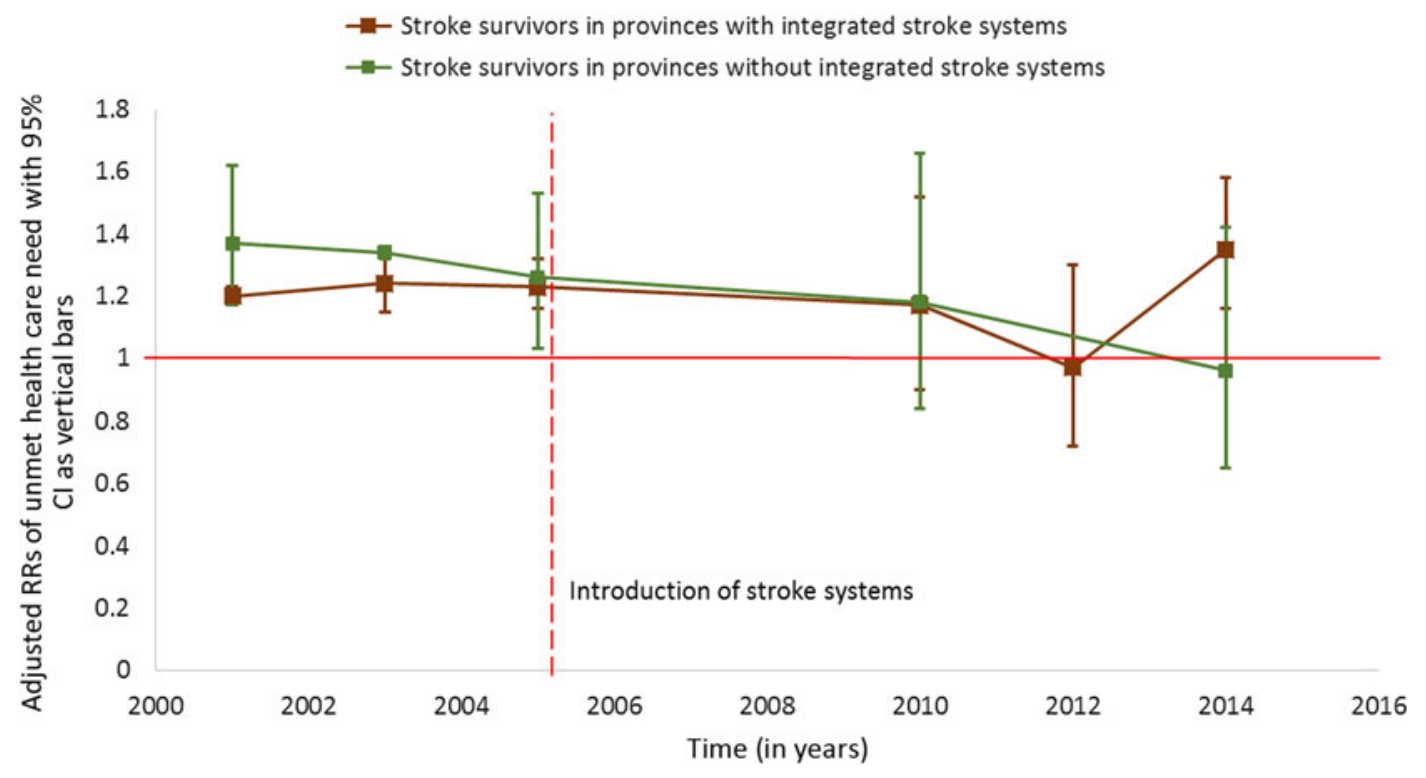

Figure 2: Unmet health care needs in Canadian stroke survivors compared to the general population over time represented as aRRs, using cross-sectional data from the Canadian Community Health Survey (2000-2014 cycles).

implementation of integrated stroke systems. However, the higher unmet health care needs in stroke survivors compared to the general population after adjusting for various factors suggest that being a stroke survivor is an independent predictor of unmet health care needs. Fourth, provinces that were classified as not having implemented integrated systems of stroke care may have employed other measures to improve stroke care. In addition, the implementation of integrated systems of stroke care was heterogeneous across provinces, we were unable to use exact dates for implementation of such systems in the regression analysis, and using a 2006 cutoff may have diluted the ability to detect the impact of these systems. We also had limited information on the actual 
Table 2: Results of log-binomial generalized estimating equation (GEE) model for unmet health care needs among Canadian stroke survivors $(n=5976)$

\begin{tabular}{l|c|c}
\hline Characteristics & $\begin{array}{c}\text { Adjusted risk ratio } \\
(\mathbf{9 5 \%} \mathbf{C I})^{*}\end{array}$ & $\boldsymbol{P}$-value \\
\hline Female (vs. male) & $1.04(0.94-1.15)$ & 0.46 \\
\hline $\begin{array}{c}\text { Immigrant (vs. } \\
\text { nonimmigrant) }\end{array}$ & $0.99(0.93-1.05)$ & 0.79 \\
\hline Ethnic minority (vs. not) & $1.01(0.93-1.10)$ & 0.82 \\
\hline
\end{tabular}

Age groups (age 60-69 years as reference)

\begin{tabular}{l|l|l}
\hline $40-49$ & $1.39(1.18-1.64)$ & $<0.001$ \\
\hline $50-59$ & $1.10(0.89-1.37)$ & 0.37 \\
\hline $70-79$ & $1.03(0.93-1.15)$ & 0.54 \\
\hline Greater than 80 & $1.11(1.00-1.23)$ & 0.056 \\
\hline
\end{tabular}

Marital status (married or common-in-law as reference)

\begin{tabular}{l|l|l}
\hline Single & $0.91(0.75-1.11)$ & 0.34 \\
\hline Separated or widowed & $0.96(0.88-1.05)$ & 0.38 \\
\hline
\end{tabular}

Income groups (>80,000 reference group)

\begin{tabular}{l|l|l}
\hline No income & $1.27(0.93-1.74)$ & 0.13 \\
\hline$<20,000$ & $1.51(1.01-2.24)$ & 0.043 \\
\hline $20-39,999$ & $1.45(1.01-2.08)$ & 0.043 \\
\hline $40-59,999$ & $1.44(1.08-1.90)$ & 0.012 \\
\hline $60-79,999$ & $1.37(0.93-2.03)$ & 0.13 \\
\hline
\end{tabular}

Education level (with postgraduate training as reference)

\begin{tabular}{l|c|c}
\hline \multicolumn{3}{l|}{ Education level (with postgraduate training as reference) } \\
\hline$<$ grade 12 & $1.05(0.93-1.20$ & 0.42 \\
\hline$>$ grade 12 & $1.04(0.93-1.17)$ & 0.46 \\
\hline \multicolumn{3}{c}{ Lifestyle factors } \\
\hline $\begin{array}{c}\text { Ever smoker (vs. never } \\
\text { smoker) }\end{array}$ & $0.91(0.85-0.99)$ & 0.012 \\
\hline Current drinker (vs. not) & $0.95(0.89-1.03)$ & 0.20 \\
\hline
\end{tabular}

Comorbid conditions (present vs. absent)

\begin{tabular}{l|c|c}
\hline Hypertension & $0.98(0.89-1.07)$ & 0.62 \\
\hline Diabetes mellitus & $1.14(1.03-1.25)$ & 0.013 \\
\hline Heart disease & $1.24(1.16-1.33)$ & $<0.001$ \\
\hline
\end{tabular}

Self-rated health (excellent as reference)

\begin{tabular}{l|c|c}
\hline Poor & $2.25(1.67-3.01)$ & $<0.001$ \\
\hline Fair & $1.68(1.28-2.22)$ & $<0.001$ \\
\hline Good & $1.28(0.98-1.69)$ & 0.073 \\
\hline Very good & $0.98(0.74-1.29)$ & 0.88 \\
\hline
\end{tabular}

Quasi-likelihood under the independence model criterion (QIC) = 6669.13 .

*Adjusted for province of residence.

success of the implementation of organized stroke systems in all provinces, and on the proportion of people with stroke who received integrated stroke care. For all of these reasons, our finding of a lack of association between stroke systems of care and reduction in unmet health care needs should not be taken as evidence of a lack of effect of such systems.

In conclusion, we found that stroke survivors have higher unmet health care needs compared to the general population, but that these needs have reduced over time. Further work is required to identify the nature of these unmet health care needs and to determine how to address them.

\section{DiscLOSURES}

MKK holds Mid-Career Investigator Awards from the Heart and Stroke Foundation of Canada. MVV holds a Fellowship Award from the Canadian Institutes of Health Research. JF does not have anything to declare.

\section{Statement of Authorship}

MVV was responsible for study conception, design of the study, data acquisition, and analysis and interpretation of results. $\mathrm{JF}$ was responsible for design of the study, and analysis and interpretation of results. MKK was responsible for study conception, design of the study, and interpretation of results. MVV wrote the manuscript that was critically assessed JF and MKK.

\section{Availability of Data and Supporting Materials Section}

Dataset including statistical code can be available from corresponding author.

\section{SuPPLEMENTARY Material}

To view supplementary material for this article, please visit https://doi.org/10.1017/cjn.2019.319

\section{REFERENCES}

1. Allin S, Grignon M, Le Grand J. Subjective unmet need and utilization of health care services in Canada: what are the equity implications? Soc Sci Med (1982). 2010;70(3):465-72.

2. Carr W, Wolfe S. Unmet needs as sociomedical indicators. Int $\mathbf{J}$ Health Serv Plan Adm Eval. 1976;6(3):417-30.

3. Feigin VL, Roth GA, Naghavi M, et al. Global burden of stroke and risk factors in 188 countries, during 1990-2013: a systematic analysis for the global burden of disease study 2013. Lancet Neurol. 2016;15(9):913-24.

4. Duxbury S, Depaul V, Alderson M, Moreland J, Wilkins S. Individuals with stroke reporting unmet need for occupational therapy following discharge from hospital. Occup Ther Health Care. 2012;26(1):16-32.

5. McKevitt C, Fudge N, Redfern J, et al. Self-reported long-term needs after stroke. Stroke. 2011;42(5):1398-403.

6. Ronksley PE, Sanmartin C, Quan H, et al. Association between chronic conditions and perceived unmet health care needs. Open Med Peer-Rev Indep Open-Access J. 2012;6(2):e48-58.

7. Bindman $\mathrm{AB}$, Grumbach $\mathrm{K}$, Osmond $\mathrm{D}$, et al. Preventable hospitalizations and access to health care. JAMA. 1995;274(4): $305-11$.

8. Schwamm LH, Pancioli A, Acker JE, et al. Recommendations for the establishment of stroke systems of care: recommendations from the American Stroke Association's task force on the development of stroke systems. Stroke. 2005;36(3):690-703.

9. Kapral MK, Fang J, Silver FL, et al. Effect of a provincial system of stroke care delivery on stroke care and outcomes. CMAJ. 2013;185(10):E483-91.

10. Ganesh A, Lindsay P, Fang J, et al. Integrated systems of stroke care and reduction in 30-day mortality. Neurology. 2016;86(10):898-904.

11. Béland Y. Canadian community health survey - methodological overview. Health Rep. 2002;13(3):6.

12. McNutt L-A, Wu C, Xue X, Hafner JP. Estimating the relative risk in cohort studies and clinical trials of common outcomes. Am J Epidemiol. 2003;157(10):940-3. 
13. Reid AY, Metcalfe A, Patten SB, Wiebe S, Macrodimitris S, Jetté N. Epilepsy is associated with unmet health care needs compared to the general population despite higher health resource utilizationA Canadian population-based study. Epilepsia. 53(2):291-300.

14. Andrew NE, Kilkenny M, Naylor R, et al. Understanding long-term unmet needs in Australian survivors of stroke. Int J Stroke. 2014;9 Suppl A100:106-12.

15. de Haan RJ, Scholte op Reimer WJM, Rijnders PT, Limburg M, van den Bos GAM. Unmet care demands as perceived by stroke patients: deficits in health care? Qual Health Care QHC. 1999;8(1):30-5.

16. Kersten P, Low JTS, Ashburn A, George SL, McLellan DL. The unmet needs of young people who have had a stroke: results of a national UK survey. Disabil Rehabil. 2002;24(16):860-6.
17. Olaiya MT, Cadilhac DA, Kim J, et al. Long-term unmet needs and associated factors in stroke or TIA survivors: an observational study. Neurology. 2017;89(1):68-75.

18. Feigin VL, Forouzanfar MH, Krishnamurthi R, et al. Global and regional burden of stroke during 1990-2010: findings from the Global Burden of Disease Study 2010. Lancet Lond Engl. 2014;383(9913):245-54.

19. Dimick JB, Ryan AM. Methods for evaluating changes in health care policy: the difference-in-differences approach. JAMA. 2014;312(22):2401-2.

20. Muggah E, Graves E, Bennett C, Manuel DG. Ascertainment of chronic diseases using population health data: a comparison of health administrative data and patient self-report. BMC Public Health. 2013;13:16. 